\title{
A CONSTITUIÇÃO DA REDE DE SENTIDOS MODERNA E A PSICOLOGIA
} Matheus Rios Silva Santos ${ }^{1}$; Laurenio Leite Sombra²

\author{
1. Bolsista PIBIC/CNPq, Graduando em Psicologia, Universidade Estadual de Feira de Santana, e-mail: \\ matheusrssantos@gmail.com \\ 2. Orientador, Departamento de Ciências Humanas e Filosofia, Universidade Estadual de Feira de Santana, e-mail: \\ lausombra@hotmail.com
}

PALAVRAS-CHAVE: Rede de Sentidos; Psicologia; Modernidade.

\section{INTRODUÇÃO}

Assim como as sociedades atuais foram sendo constituídas por longos e complexos processos de dominação, relações de poder e antagonismos, o conceito de sujeito ocidental se forjou por uma série de processos de subjetivação e articulação de signos que nos permitem, hoje, investigá-lo. Gestada por um longo período desde a antiguidade clássica, a categoria moderna de sujeito foi sendo conformada ao longo de toda a história ocidental. Um estudo genealógico pode demonstrar que a concepção clássica de psyché, posteriormente entendida como alma ou como espírito; a separação corpo/alma; as mudanças na categoria de homem; o conceito de cogito cartesiano; os processos de colonização ou de conquista do "Novo Mundo"; grandes correntes do pensamento ocidental a partir do século XVIII, como o Iluminismo e o Romantismo; todos estes aspectos influenciaram na conformação da moderna ideia de sujeito.

Neste sentido, esta pesquisa, partindo do conceito de rede de sentidos desenvolvido por Sombra (2015a; 2015b; 2017), objetivou estudar como se deu a constituição da rede de sentidos moderna. De modo mais específico, estudamos como a categoria de sujeito foi ganhando cada vez mais valor dentro dessa rede e de que forma a Psicologia recorre a ela para construir suas teorias sobre o sujeito.

É importante deixar claro que essa configuração não se deu de modo pacífico e linear, mas sempre marcada por disputas, rupturas e processos de antagonismo, como é inerente ao campo social. Por isso, recorremos ao conceito de colonialidade do poder, desenvolvido pelo sociólogo Aníbal Quijano, para compreendermos como os signos da cultura europeia passaram a se sobrepor sobre os signos das demais culturas, principalmente, em se tratando de América Latina.

A leitura dos textos deste sociólogo também foi fundamental para situarmos historicamente a emergência da modernidade, compreendendo o papel da América Latina neste processo. Ainda se tratando da modernidade, não poderíamos deixar de demarcar a importância daquelas que são consideradas as duas revoluções individualistas dos tempos modernos: o Iluminismo e o Romantismo. Por fim, fizemos uma breve discussão recorrendo ao Behaviorismo e à Psicanálise para explanarmos como estas Escolas psicológicas foram influenciadas pelos signos da rede de sentidos moderna.

\section{METODOLOGIA}

O método utilizado na pesquisa foi a revisão bibliográfica de textos e livros. Para isso, identificamos os autores e as obras que contribuiriam para a nossa compreensão da rede de sentidos moderna, realizamos fichamento, análise e uma síntese que ganhou forma de artigo como resultado da presente pesquisa.

Para melhor compreendermos o conceito de rede de sentidos, os textos "Identidade dos sujeitos: linguagem, constituição de sentido e valor" (2015a); "Escândalo da política brasileira: o sentido da desigualdade" (2015b) e "O Ocidente 
como problema filosófico” (2017) escritos por Laurenio Sombra foram essenciais para tal.

Compreendido o conceito de rede de sentidos, partimos para investigar quais signos passaram a compor a modernidade e como foi se dando a conformação da ideia de sujeito, em última instância, sua rede de sentidos. Para esta empreitada, recorremos ao livro $A$ invenção do psicológico: quatro séculos de subjetivação 1500-1900 (2012a) de Luís Cláudio Figueiredo e ao livro As fontes do Self: a construção da identidade moderna (1997), do filósofo canadense Charles Taylor.

Logo após, buscamos livros e textos que tratavam sobre a epistemologia da Psicologia. Neste sentido, o livro Introdução à Epistemologia da Psicologia (1982) foi bastante importante, principalmente para compreendermos as três concepções de homem do ocidente. Recorremos também a dois textos de Paul Mengal: "Para uma história da Psicologia" (1988) e "Nascimentos da Psicologia: a natureza e o espírito" (1994), para estudarmos a conformação da Psicologia como ciência.

Vale destacar também que ao longo da pesquisa entramos em contato com os textos de Aníbal Quijano: "Colonialidade do poder, Eurocentrismo e América Latina” (2005) e "Colonialidade e modernidade-racionalidade" (2006); e o livro 1492: O Encobrimento do Outro (A Origem do "Mito da Modernidade"): Conferências de Frankfurt (1993), de Enrique Dussel, que trouxeram uma importante contraposição para pensarmos o processo de antagonismo gerado entre o contato dos europeus, seus valores e signos com os demais povos, com ênfase nos povos da América.

\section{DISCUSSÃO}

$\mathrm{Na}$ nossa investigação sobre o conceito de rede de sentidos, percebemos que seu elemento essencial é o signo: de modo geral, eles podem ser considerados "instrumentos" captáveis pelos sentidos por um determinado grupo social, forjados artificialmente e identificáveis como o mesmo ao longo do tempo. Sombra (2015a, p. 99) assinala que os signos não são organizados isoladamente. Pelo contrário, eles são dispostos em uma rede de intencionalidade e valorações que é definida por ele como "rede de sentidos". Inerentes a essa rede estão atributos como a normatividade, a direcionalidade, a sua natureza intersubjetiva e social. Além desses, a rede de sentidos gera antagonismo ao entrar em contato com outras redes. Este antagonismo pode ser gerado por signos divergentes entre duas ou mais redes de sentidos ou até mesmo pelo grau de valoração diferente de um signo no sistema de classificação de redes diferentes. O sistema de classificação depende de fatores ligados à temporalidade e à historicidade.

Por isso, buscamos demonstrar, através das três concepções de homem apontadas por Japiassu (1982), como o signo "homem" foi sendo valorado de diversas formas ao longo das três diferentes concepções: a clássica, a cristã e a moderna. Ainda sobre o elemento da historicidade, foi bastante instrutivo a explanação que Taylor (1997) realiza sobre a emergência da "interioridade" ligada à concepção cristã de homem. Em última instância, era este signo que permitia o acesso ao signo de Deus, que ocupava o topo da cadeia valorativa durante o período medieval.

Quanto à rede de sentidos moderna, é importante demarcar que a referência à categoria de sujeito ocidental circunscreve uma rede de sentidos forjada a partir de um espaço determinado, a Europa Ocidental, base geográfica do que foi progressivamente nomeado como "ocidente". Nesse contexto, a referência à categoria de sujeito moderno está vinculada a uma condição específica que foi sendo formada a partir da conjunção de vários eventos e fatos históricos que se sucederam principalmente a partir do século XVI e que têm como epicentro, segundo a interpretação de certos autores (DUSSEL, 1993; QUIJANO, 2005), a chegada dos povos europeus ao continente americano. 
O contato entre colonizadores europeus e os povos nativos do continente americano gerou um profundo processo de antagonismo, que é considerado por Dussel (1993, p. 23) como fator histórico fundamental para a reestruturação da percepção europeia da sua subjetividade. A América Latina seria, portanto, a "Alteridade essencial da Modernidade" (DUSSEL, 1993, p. 23).

Há de se pensar também que o êxito europeu em disseminar e sobrepor a sua rede de sentidos à dos demais povos colonizados se deveu a um elemento-chave da colonização europeia, aquele que Quijano (2005) denomina "colonialidade do poder". A colonialidade do poder funcionou, portanto, como elemento central no processo de sedução, convencimento e/ou imposição da pretensa superioridade e universalidade dos valores e signos da rede de sentidos moderna.

Do ponto de vista filosófico, é fundamental o pensamento de René Descartes para se pensar o conceito de sujeito moderno. Assim, a forma como Descartes constrói o cogito moderno permite o resgate de um dos signos pertencente à concepção clássica de homem: o signo da interioridade. Descartes é um dos maiores expoentes na conformação da dualidade-chave para a geografia do sujeito moderno: dentro/fora; interior/exterior. Assim, a construção teórica cartesiana possibilita toda uma formação de um ambiente subjetivamente interno para o homem moderno.

Inseridos na modernidade, estão duas importantes correntes de pensamentos: o Iluminismo e o Romantismo. O Iluminismo consolida o signo de indivíduo, que passa a ser entendido como átomo social, elemento constitutivo da organização social; e o signo de progresso que, ao ser incorporado à rede de sentidos moderna, permite que outros signos possam ser modificados e/ou desenvolvidos, tais como "evolução", "civilização", "humanidade" e "história". Quanto à rede de sentidos do Romantismo, esta estaria ligada a aspectos não objetificáveis do sujeito, tais como seus impulsos, sentimentos e características individuais genuínas. Por outro lado, é importante reconhecer que foi fundamental para o ideal romântico de homem manter signos caros à modernidade, como a interioridade e a ideia de sujeito, de modo a possibilitar a emergência da subjetividade/personalidade - tal como a Psicologia propõe como um dos seus objetos de investigação.

Coube, por fim, avaliar mais especificamente como a Psicologia, enquanto campo do conhecimento, influi diretamente na arquitetura dos signos através da formulação de teorias e hipóteses sobre os sujeitos humanos; de que modo esses signos se tornam parte integrante da rede de sentidos, ao serem assimilados pelos sujeitos ocidentais; e como essa rede influi diretamente na constituição desses sujeitos ao gerar novas percepções e modos de estar no mundo.

Colocando em termos práticos, duas escolas psicológicas se apresentam como nomeadamente antagônicas na organização dos seus signos quanto às bases epistemológicas, concepções de homem e método: o Behaviorismo Radical e a Psicanálise. De fato, tanto o Behaviorismo quanto a Psicanálise são exemplos bem instrutivos para se perceber como a Psicologia influi diretamente na arquitetura dos signos através da formulação de teorias, hipóteses e demais formulações sobre os sujeitos humanos. Há de se pensar que o sujeito que procura uma terapia na qual psicólogo se reconhece como analista do comportamento passa a incorporar a rede de sentidos forjada pelo Behaviorismo. Essa incorporação o leva a interpretar a si e ao seu ambiente com base na gramática e arquitetura dos signos do Behaviorismo, gerando, portanto, percepções e modos de estar no mundo a partir dessa rede. De igual modo, o sujeito que em uma sessão terapêutica psicanalítica busca compreender "o sonho que teve na noite passada" a partir da interpretação do psicanalista passa a ser incorporado pela série de signos que a Psicanálise utiliza para explicar a articulação dos materiais 
oníricos durante o sono em "um local" chamado "inconsciente". Assim, não é demais afirmar que Psicologia (leia-se escolas da Psicologia) detém certa colonialidade do poder sobre o sujeito moderno.

\section{CONSIDERAÇÕES FINAIS}

Diante dos resultados e da discussão realizada, consideramos que demos um primeiro passo na compreensão de como a Psicologia "coloniza" os sujeitos a partir de suas fundamentações teóricas que, na maioria das vezes, foram construídas a partir dos signos da rede de sentidos moderna europeia. Trata-se, portanto, de realizar a crítica sobre esse modo de produzir e reproduzir um conhecimento científico, sem deixar de verificar como ele privilegia determinado grupo social em detrimentos dos demais.

Ponderamos que realizar esta autocrítica é fundamental para a Psicologia voltar seus interesse para signos que estão presentes em redes de sentidos de outros povos ao redor do mundo e que, eventualmente, não são levados em consideração, justamente por pertencer à rede de sentidos do colonizador. Ao redirecionar seus estudos para essas redes de sentidos, será possível almejar que a Psicologia se proponha a compreender os sujeitos a partir de suas próprias redes de sentidos e não continuando a ser um instrumento de disseminação de uma rede de um único povo.

\section{REFERÊNCIAS}

DUSSEL, Enrique. 1492: O Encobrimento do Outro (A Origem do "Mito da Modernidade"): Conferências de Frankfurt. Tradução de Jaime A. Ciasen. Petrópolis, Vozes, 1993.

FIGUEIREDO, Luís Cláudio M. A invenção do psicológico: quatro séculos de subjetivação 1500-1900. 8. ed. São Paulo, SP: Escuta, 2012a.

. Matrizes do pensamento psicológico. 18. ed Petrópolis, RJ: Vozes, $2012 \mathrm{~b}$.

JAPIASSU, Hilton. Introdução à Epistemologia da Psicologia. 3.ed. rev. e amp Rio de Janeiro: Imago, 1982.

MENGAL, P. "Para uma história da Psicologia". Revue de synthese: IV e S. Traduzido por Marcio Luiz Miotto (UFF-RPS) e revisado por Maria Inez de Souza. No 3-4, julho-dezembro de 1988

"Nascimentos da Psicologia: a natureza e o espírito". Revue de synthese: IV

S. Traduzido por Marcio Luiz Miotto (UFF-RPS) e revisado por Pedro Cattapan (UFF-RPS). N 3-4, julho-dezembro de 1994.

QUIJANO, Aníbal. "Colonialidade do poder, Eurocentrismo e América Latina". In: LANDER, Edgardo (Org.). A colonialidade do saber: eurocentrismo e ciências sociais. Perspectivas latino-americanas. Buenos Aires. CLACSO, Consejo Latinoamericano de Ciencias Sociales, 2005.

"Colonialidade e modernidade-racionalidade". In: BONILLA, Heráclito

(Org.). Os conquistados: 1492, e a população indígena das Américas Tradução de Magda Lopes - São Paulo: Hucitec, 2006.

SOMBRA, Laurenio. "Identidade dos sujeitos: linguagem, constituição de sentido e valor". Revista Sísifo. Feira de Santana-BA, v.1 n. 2, 2015a.

"Escândalo da política brasileira: o sentido da desigualdade". Revista Ideação, n.32, Jul./Dez. 2015 b.

2017.

. "O Ocidente como problema filosófico". Revista Ideação, n.35, Jan./Jun.

TAYLOR, Charles. As fontes do self: a construção da identidade moderna; Trad. Adail Ubirajara Sobral, Dinah de Abreu Azevedo. - São Paulo: Loyola, 1997. 